\title{
Preference Heterogeneity and Habit Persistence: The Case of Breakfast Cereal Consumption*
}

\author{
Linda Thunström \\ Department of Economics, Umeå University, SE-901 87 Umeå, Sweden.
}

Working Paper No.738

\begin{abstract}
This paper estimates the strength and heterogeneity across households in state dependence associated with breakfast cereal consumption, where positive state dependence implies habit persistence and negative state dependence implies variety-seeking in consumption. The analysis relies on a discrete choice model and finds that breakfast cereal consumption is generally highly habitual, but the degree of habit persistence exhibits heterogeneity across households. In addition, some households can be characterized as variety-seeking. The strength of habit persistence is similar across income and educational groups. The strength of habit persistence seems to be weaker for households with several adults and children compared to one-adult-households.
\end{abstract}

Keywords: consumer choice; habit persistence; food consumption; preference heterogeneity

JEL classification: D12; C35

\footnotetext{
* I thank Thomas Aronsson, Laura M. Andersen, Kurt Brännäs, David Granlund, Jonas Nordström, and Niklas Rudholm for helpful comments and suggestions. I also thank the participants at the $2^{\text {nd }}$ HUI research workshop in Stockholm and the participants at a seminar at the department of economics at Umeå University. Financial support from the Swedish Research Council for Environment, Agricultural Sciences and Spatial Planning is gratefully acknowledged.
} 


\section{Introduction}

Recently, modern diets have become a major concern among researchers, public health experts and policy makers. The modern diet, often characterized by a poor nutritional content and a high amount of so called "empty calories," has contributed to the increased prevalence of a number of serious illnesses and subsequent costs for individuals and society. ${ }^{1}$ A high consumption of empty calories means frequent sharp rises in blood glucose (sugar) concentrations, which is associated with an increased risk for type 2 diabetes (Salmeron et al., 1997a and 1997b) and cardiovascular disease (Liu et al., 2000). In contrast, a high intake of whole grain products has several health-promoting effects. For example, it has been shown to reduce the risk of obesity (Liu et al., 2003), itself a major risk factor for type 2 diabetes, cardiovascular disease, and colorectal cancer (Schatzkin et al., 2007).

Launching information campaigns that make consumers aware of the positive health effects from choosing food that is rich in whole grain may be of interest to policy makers and producers. Some health advocates have suggested incentives for redirecting food consumption, such as food taxes. However, the efficiency of both information campaigns and economic policies will be affected by the degree of habit persistence in food consumption.

This paper examines the strength and heterogeneity in the habit persistence associated with breakfast cereal consumption. Studies show (e.g. Jenkins et al., 1982, and Liljeberg et al., 1999) that the choice of breakfast affects the blood glucose response not only to the morning meal itself, but also to subsequent meals during that day. The choice of breakfast is, therefore, an important decision for those in charge of household purchases. Nilsson et al. (2008) analyze the health benefits from consuming different types of breakfast cereals specifically. Using a breakfast containing white-wheat bread as the baseline, they show that whole-grain cereal products for breakfast notably increase the glucose tolerance, i.e. stabilizes the blood

\footnotetext{
${ }^{1}$ Direct costs on health care (costs of in- and outpatient care and pharmaceutical therapy) from poor nutrition and too little exercising are estimated to account for 7 percent of personal health care expenditures in the U.S. (Kenkel and Manning, 1999). In Sweden, the direct costs on the public health care system of obesity and overweight alone has been estimated to be SEK 3.6 billion (Persson et al. 2004), and the corresponding indirect costs (the value of lost production, due to sick leave, disability pension and early deaths) to be SEK 12.4 billion (Persson and Ödegaard, 2005), amounting to about 3 percent of total indirect and direct costs of all illnesses (Socialstyrelsen, 2003). Diet-related costs on society are likely to increase even further, due to the time lag between poor dieting and the development of severe illnesses. These developments have put pressure on policy makers to consider policies that encourage healthier food consumption.
} 
glucose levels throughout the day. Therefore, a regular diet of whole-grain cereal products for breakfast reduces the risk of type 2 diabetes and cardiovascular disease.

To analyze habit persistence in breakfast cereal consumption, a mixed multinomial logit model (also known as the random parameters logit model) is applied to Swedish household panel data on breakfast cereal purchases. The model allows for state dependence, where a positive state dependence implies habit persistence in consumption, whereas a negative state dependence implies variety-seeking.

Pollack (1970) notes that goods are associated with habit persistence if current preferences depend on past consumption. ${ }^{2}$ Thus, habit persistence means that past consumption reinforces the propensity to consume the same good over time. If food consumption is habitual, short and long term responses to income and price changes, and possibly also information campaigns, will differ (even if the underlying decision problem lacks other intertemporal aspects). If consumption is associated with habit persistence, price changes or information campaigns will lead to changes in consumption, which will lead to changes in tastes, which, in turn, will lead to further changes in consumption. In other words, in the short run, consumption is sticky, and adjusts less by comparison with the long run response (which also reflects adjustments of habits). If the habit persistence is strong, policies designed to affect consumption will, therefore, be more costly, and price changes will have little effect in the short run, compared to cases where the habit persistence is weak. A negative state dependence, on the other hand, implies variety-seeking. Consumers that seek variety in food consumption experience satiety over time from the attributes associated with a good, which creates incentives to change the consumption behavior. The short and long term effects on consumption of information campaigns and price instruments may, therefore, depend on whether or not consumption is driven by habit persistence or by variety-seeking.

Research on habits in food consumption has largely been based on aggregate data. The reason for this might be lack of access to adequate micro level data (Carrasco et al., 2005, and Browning and Collado, 2007). A few studies have focused on habit persistence in consumption, using micro level data (e.g. Alessie and Kapteyn, 1991, Meghir and Weber, 1996, Dynan, 2000, Carrasco et al., 2005, and Browning and Collado, 2007). Evidence of

\footnotetext{
${ }^{2}$ We choose to use the term 'habit persistence' instead of 'habit formation', since we do not address the formation of habits as such.
} 
habit persistence in food consumption from these studies is mixed. Carrasco et al. (2005) find evidence of habit persistence in aggregate food consumption, whereas Alessie and Kapteyn (1991), Meghir and Weber (1996) and Dynan (2000) do not. Browning and Collado (2007) find that aggregate food consumed away from home exhibits habit persistence, whereas food consumed at home does not. However, the level of product aggregation in these studies is high, which makes the results less useful as a basis for policy design -- particularly if the policy instruments are designed to target consumption of certain food categories. By aggregating the consumption of food categories associated with varying degrees of habit persistence, habits may be difficult to detect.

Studies on detailed product data that contain measures of state dependence and use discrete choice models are mainly found in the marketing literature on brand choice; see Chintagunta (1993), Erdem (1996), Ailawadi and Neslin (1998), Sun et al. (2003) and Seetharaman (2004). These studies analyze brand choice on (mainly region-specific) US micro level data, containing selected brands. The food product categories covered by these studies are margarine, peanut butter, ketchup and yoghurt. Seetharaman defines the influence of the previous purchase on the propensity to purchase the same brand as "structural habit persistence". The results from the above mentioned studies suggest habit persistence associated with brands or attributes in the consumption of all food groups mentioned.

A few recent studies use mixed multinomial logit models to analyze unobserved preference heterogeneity in food demand; Nevo (2001) and Chidmi and Lopez (2007) estimate mixed multinomial logit models on breakfast cereal scanner data, whereas Andersen (2006) estimate a mixed multinomial logit model using household panel data on the demand for eggs. Neither of the studies allows for habit persistence, but all find evidence of heterogeneity in consumer preferences over breakfast cereals.

The present study contributes to the literature in two ways. It is the first study exploring habit persistence on data where healthy and unhealthy food products are identified. Second, it is the first study allowing for heterogeneity in habit persistence on data that contains both detailed product information and background information on consumers. Therefore, we are able to explore the extent to which household characteristics explain the heterogeneity in state dependence, i.e. we identify differences in state dependence over household groups. Knowledge on variations in habit persistence over household groups is valuable to 
policymakers who wish to give priority to certain households in the design or implementation of policy. ${ }^{3}$ The results generated by this study may help in identifying the Swedish consumer groups that are likely to be most responsive - in the short run - to policies designed to influence the nutritional value of breakfasts.

The structure of the paper is as follows. Section 2 presents the data, Section 3 describes the empirical method, and Section 4 provides the estimation results. Section 5 contains concluding remarks.

\section{Data}

The study relies on household panel data for daily breakfast cereal consumption during year 2003, obtained from the market research institute GfK Sweden ${ }^{4}$. One member of each household in the panel is assigned the responsibility of reporting food purchases on a detailed level. Product characteristics of the breakfast cereals are reported by the sample households, and include the price of the product purchased, date of purchase, brand, package size and the number of packages bought. The number of breakfast cereal products in the sample amounts to 181 . The detailed data allow us to match each product with its nutritional content, by using the database maintained by the Swedish National Food Administration (SLV). Each product is matched with its content of fat, saturated fat, fibre, salt, sugar and added sugar (measured per 100 grams of product).

To simplify the analysis of choice determinants for different cereals, we group the 181 breakfast cereals into 5 categories, based on product content and characteristics: flakes, Keyhole labelled (particularly healthy) breakfast cereals, muesli, sweet breakfast cereals and others. $^{5}$ The main variation of characteristics between these groups is in sugar and fibre

\footnotetext{
${ }^{3}$ For instance, Nordström and Thunström (2008) show that households with children have a lower consumption share of healthy bread and breakfast cereals than households without children. Encouraging families with children to improve their diets might therefore be a priority. Another reason for giving priority to families with children emerges if habits are formed at an early age and are likely to stick over the life cycle.

${ }^{4}$ GfK ('Growth from Knowledge') is a private market research company.

${ }^{5}$ The Keyhole is a nutrition symbol certified by the Swedish National Food Administration (SLV) that identifies healthy food alternatives. In 2003, breakfast cereals obtained a Keyhole symbol if they fulfilled the following criteria: sugar max 13g/100g and fibre min 9g/100g (SLVFS,1989:2). In our sample, the products included in the Keyhole group are those breakfast cereals that fullfil these criteria (mainly flakes and muesli). The flakes group contains flakes (other than Keyhole labelled) that are non-sweet (e.g. cornflakes and bran flakes), whereas the sweet flakes (e.g. frosties) are included in the sweet breakfast cereal group. The latter group also contains all breakfast cereals that are primarily marketed as kids cereals. The products in the muesli group (i.e. the muesli
} 
contents. Table 1 shows summary statistics (min, mean and max values) of the product characteristics for the products in each category. For example, the price of the cheapest Keyhole-labelled product purchased (by all households in the sample) was SEK 3.45 per 100 gram, whereas the price of the most expensive Keyhole-labelled product was SEK 6.95 per 100 gram. The mean price over the year for Keyhole-labelled cereals was SEK 5.21. ${ }^{6}$ The average fibre content is higher in the muesli category than in Keyhole-labelled breakfast cereals. However, the fibre-rich products in the muesli category did not meet the Keyhole label criteria for sugar content. The product content is used to divide the breakfast cereals into their respective groups but, as will be shown later, the product content is not used in the econometric analysis, due to too little variation in the fibre and sugar content within the groups.

Table 1. Breakfast cereal characteristics

\section{Breakfast cereal type}

\begin{tabular}{|c|c|c|c|c|c|c|}
\hline \multicolumn{2}{|l|}{ Characteristic } & Flakes & $\begin{array}{l}\text { Keyhole } \\
\text { labelled }\end{array}$ & Muesli & $\begin{array}{l}\text { Sweet } \\
\text { cereals }\end{array}$ & Others \\
\hline \multirow{3}{*}{ Price in SEK per 100 gram } & $\min$ & 4.17 & 3.45 & 2.69 & 4.56 & 3.84 \\
\hline & mean & 4.72 & 5.21 & 3.50 & 5.28 & 5.28 \\
\hline & $\max$ & 5.21 & 6.95 & 3.89 & 6.23 & 11.29 \\
\hline \multirow{3}{*}{ Grams of fibre per 100 gram } & $\min$ & 1.8 & 9.7 & 6.8 & 1.2 & 0.8 \\
\hline & mean & 3.4 & 10.5 & 10.7 & 2.6 & 5.9 \\
\hline & $\max$ & 14.7 & 11.0 & 14.7 & 4.0 & 7.7 \\
\hline \multirow{3}{*}{ Grams of sugar per 100 gram } & $\min$ & 9.3 & 1.8 & 17.0 & 9.4 & 0.4 \\
\hline & mean & 13.6 & 7.2 & 23.4 & 38.5 & 24.3 \\
\hline & $\max$ & 38.0 & 11.0 & 24.8 & 45.9 & 38.0 \\
\hline
\end{tabular}

Household characteristics in the sample include the level of education and gender of the household member mainly responsible for food purchases, the pre-tax labour income ${ }^{7}$ of the household, the number of household members and the number of children age 16 or younger. The measure of household income refers to the pre-tax labor income in 2003 and is presented in such a way that the households are divided into income groups. Households with a

without the Keyhole label) range from very basic muesli to different types of muesli with both berries and fruit and roasted ingredients.

${ }^{6}$ Keyhole labelled muesli is relatively cheap, whereas Keyhole labelled flakes are relatively expensive.

${ }^{7}$ Reported in 2003 years prices. 
maximum income of SEK 199,999 belong to income group 1, whereas households in income groups 2, 3 and 4 have an income of SEK 200,000-299,999, SEK 300,000-499,999 and minimum SEK 500,000 respectively. Households are divided into three educational groups, based on the highest level of education of the person in charge of household purchases; elementary schooling, high school education and higher education (university/college). ${ }^{8}$ Also, households are divided into household types; single adult (man or woman) with no children, single adult with children, two adults with no children, two adults with one child, two adults with two or more children, and three or more adults (with or without children), where adult is defined as above 16 years old. Table A1, Appendix A, provides an overview of the variable definitions.

In 2003, 1,336 households in the GfK panel purchased grain products for the full year, of which 926 purchased breakfast cereals. These households purchasing breakfast cereals constitute our population and the basis for our analysis. The panel is highly unbalanced, with the frequency of reported annual household breakfast cereal purchases ranging between 1 to 123, with the highest numbers representing extreme cases. The average number of purchases made by the sample households over the year is 12 . All in all, the panel used in the analysis consists of 11,109 observations.

Following previous studies (e.g. Erdem, 1996, Seetharaman, 2004, and Andersen, 2006), we choose not to include a zero-purchase option, meaning that we exclude households who do not purchase breakfast cereals during the study period. Households always have the choice not to make a purchase, so choice occasions for a zero-purchase option are difficult to define. It is unlikely that households who are breakfast cereal consumers purchase breakfast cereals less frequently than once a year. The selection bias created by excluding households who have not purchased breakfast cereals during 2003 is therefore likely to be small. Even though we make no attempt to generalize our findings beyond breakfast cereal consumers, Appendix A contains a comparison of the relative shares of the household types in our sample, to the relative share of the same household types in the grain consumer panel as a whole (see Table A2, in Appendix A). The demographic profile of the households included in our analysis is similar to the profile of households in the full grain consumer GfK panel. The share of

\footnotetext{
${ }^{8}$ Note that the level of education is reported by the households. In the questionnaire, it is not specified whether, for instance, "higher education" means having taken courses at the university or having a degree from a university. To be more specific, the households were asked to mark their "highest ongoing or finished education", among the alternatives summarized by the dummy variables representing educational levels.
} 
households with children, and the share of households belonging to the higher income groups, are, however, slightly higher in our sample during the study period. ${ }^{9}$

Table 2 shows descriptive statistics of the shares purchased of different types of breakfast cereals by each household type. The numbers refer to the share of respective cereal types out of the total cereal consumption (in grams) for each household type. Of all breakfast cereals purchased by our sample in 2003, 39 percent were muesli, 33 percent were flakes, 15 percent were sweet cereals and 8 percent were Keyhole-labelled breakfast cereals. Dividing the households by income group, Table 2 shows that the two lowest income groups have a slightly higher percentage of Keyhole-labelled purchases ( 9 percent), as part of their total breakfast cereal purchases during the year than do the two higher income groups (7 percent).

Grouping the sample households by educational level of the household member mainly responsible for food purchases, we find that the consumption share of Keyhole-labelled breakfast cereals is higher in households where the purchaser has at least a high school education (9 percent), compared to households where the purchaser has an elementary school education (6 percent). Also, the consumption share of muesli is higher for the sample households belonging to the higher educational groups, whereas the opposite is true for flakes. The consumption share of sweet cereals is the highest for households with a high school education, compared to households belonging to both the higher and lower educational group.

Dividing the sample households by household type (i.e. combination of adults and children), Table 2 shows that the relative share of sweet cereals for households with children is sizeable (for a single adult with children, as high as 35 percent), whereas it is low (6 percent) for single adults with no children. Households consisting of a single adult without children also purchase the highest share of Keyhole-labelled breakfast cereals (12 percent) of all household types.

\footnotetext{
${ }^{9}$ We have also estimated a probit model based on the full grain GfK panel, where the decision to purchase/not to purchase breakfast cereals is a function of breakfast cereal prices and household characteristics. Compared to a model with no regressors (i.e. with only a constant), the probit model is statistically significant (LR value $=112$, $p$-value $=0.000$ ). The explanatory power of the model is relatively modest, though, with an R-squared value of 0.08. Commenting on the statistically significant (at the 5 percent level) variables only, the probit results imply that the probability of purchasing breakfast cereals increases with the number of children and with income.
} 
Table 2. Relative shares of breakfast cereal purchases by household groups

Breakfast cereal type

\begin{tabular}{|c|c|c|c|c|c|c|}
\hline & Flakes & $\begin{array}{l}\text { Keyhole- } \\
\text { labelled }\end{array}$ & Muesli & $\begin{array}{l}\text { Sweet } \\
\text { cereals }\end{array}$ & Others & Sum \\
\hline Relative market shares, all households & 0.33 & 0.08 & 0.39 & 0.15 & 0.05 & 1.00 \\
\hline \multicolumn{7}{|l|}{$\begin{array}{l}\text { Relative market shares by income per } \\
\text { household }\end{array}$} \\
\hline Income group 1 (lowest) & 0.31 & 0.09 & 0.43 & 0.13 & 0.04 & 1.00 \\
\hline Income group 2 & 0.35 & 0.09 & 0.38 & 0.11 & 0.06 & 1.00 \\
\hline Income group 3 & 0.34 & 0.07 & 0.37 & 0.16 & 0.05 & 1.00 \\
\hline Income group 4 (highest) & 0.31 & 0.07 & 0.43 & 0.16 & 0.03 & 1.00 \\
\hline \multicolumn{7}{|l|}{$\begin{array}{l}\text { Relative market shares by level of } \\
\text { education for household member } \\
\text { responsible for food purchases }\end{array}$} \\
\hline Elementary schooling & 0.42 & 0.06 & 0.35 & 0.13 & 0.06 & 1.00 \\
\hline High school education & 0.32 & 0.09 & 0.39 & 0.17 & 0.04 & 1.00 \\
\hline Higher education & 0.30 & 0.09 & 0.43 & 0.13 & 0.05 & 1.00 \\
\hline Educational level n.a. & 0.33 & 0.02 & 0.45 & 0.16 & 0.03 & 1.00 \\
\hline \multicolumn{7}{|l|}{$\begin{array}{l}\text { Relative market shares by household } \\
\text { type }\end{array}$} \\
\hline Single adult, no children & 0.32 & 0.12 & 0.46 & 0.06 & 0.04 & 1.00 \\
\hline Single adult with children & 0.15 & 0.08 & 0.37 & 0.35 & 0.05 & 1.00 \\
\hline Two adults, no children & 0.41 & 0.07 & 0.43 & 0.06 & 0.04 & 1.00 \\
\hline Two adults with one child & 0.27 & 0.06 & 0.43 & 0.19 & 0.06 & 1.00 \\
\hline $\begin{array}{l}\text { Two adults with two or more } \\
\text { children }\end{array}$ & 0.30 & 0.08 & 0.31 & 0.24 & 0.06 & 1.00 \\
\hline Three or more adults & 0.33 & 0.07 & 0.36 & 0.20 & 0.05 & 1.00 \\
\hline
\end{tabular}

Note: n.a. = not available, meaning that households did not report the category they belong to. 


\section{An Empirical Approach to Consumer Choice}

The mixed multinomial logit model (MMNL) is well suited for our purposes due to the flexibility provided by the model and its ability to handle panel data. The MMNL shares some of the features of the more commonly used, but also more restrictive, multinomial logit model (MNL).

The MMNL, as well as other models in the family of multinomial logit models, are derived from the theoretical framework provided by the random utility model (RUM). In the RUM, the utility of a choice alternative, $j$, for household $n$ in period $t$, is determined by factors that are observed by the researcher, $x_{n j t}$, and factors that are unobserved by the researcher, $\varepsilon_{n j t}$. The unobserved part of utility, $\varepsilon_{n j t}$, is defined as a random variable. It should be noted that $\varepsilon_{n j t}$ is assumed to be known to the household. The utility that the household associates with a particular choice alternative is, therefore, not subject to randomness. The household chooses among $J$ options the alternative from which it derives the highest utility. ${ }^{10}$

In a MNL, the unobserved part of the utility mentioned above (i.e. the error term) is assumed to be extreme value as well as identically and independently distributed (iid). The iid assumption means no correlation between error terms over alternatives, i.e. the unobserved utility component associated with alternative $j, \varepsilon_{n j t}$, does not affect the utility of any other choice alternative, and there is no correlation of error terms over time. The iid assumption, in turn, gives rise to the Independence of Irrelevant Alternatives (IIA) property, which states that the ratio of probabilities of any two alternatives in the model will remain unchanged, regardless of whether new alternatives are introduced or existing alternatives are excluded from the choice set. Assume, for instance, that Keyhole-labelled muesli was removed from the market. From the IIA property it then follows that the households that previously purchased Keyhole-labelled breakfast cereals would divide themselves over the other breakfast cereal types in proportion to the relative shares of these breakfast cereals, such that the probability ratios are kept constant. However, households that previously purchased Keyhole-labelled breakfast cereals might differ from the general population and exclusively buy muesli and flakes (and no sweet cereals), if Keyhole-labelled breakfast cereals were not

\footnotetext{
${ }^{10}$ Here, it is assumed that the choice made by the household is the choice that gives the highest joint utility for all household members.
} 
available. The IIA associated with the MNL, therefore, imposes unnecessary and often implausible restrictions on the substitution patterns of households. A more flexible model that relaxes the iid assumption (and, as a consequence, the IIA) is desirable.

The MMNL fully relaxes the iid assumption, and hence lacks the restrictions imposed by the IIA property. ${ }^{11}$ Depending on the specification, the MMNL allows the unobserved part of the utility to be correlated over time and over alternatives. Another appealing feature of the MMNL, as demonstrated below, is that it allows for heterogeneity in preferences over consumers. MMNL calculations are very computer intense, which explains their limited use until relatively recently. Applications of MMNL models on panel data include Erdem (1996), Bath (1997), Revelt and Train (1998), and Johannesson and Lundin (2002).

The behavioural specification of the MMNL can vary extensively and, depending on the specification of the model, the MMNL can approximate any discrete choice model (McFadden and Train, 2000). For instance, a MMNL where all parameters are fixed collapses to a MNL and Hensher et al. (2007) show that a MMNL defined as an error components model approximates the nested logit model.

In the MMNL, household $n$ 's indirect utility of purchasing breakfast cereal type $j$ at time $t$ is defined as

$$
U_{n j t}=\beta_{n}^{\prime} X_{n j t}+\varepsilon_{n j t}=\left(\bar{\beta}^{\prime}+\mu_{n}^{\prime}\right) X_{n j t}+\varepsilon_{n j t}=\bar{\beta}^{\prime} X_{n j t}+\mu_{n}^{\prime} X_{n j t}+\varepsilon_{n j t}
$$

where the parameter vector $\beta_{n}$ is assumed to be household specific, i.e. the preferences may be heterogeneous over households. The parameter vector $\beta_{n}$ consists of two parts: $\bar{\beta}$, which is common to all households and equal to the mean of the distribution of all individual $\beta_{n} \mathrm{~s}$, and a household-specific error term, $\mu_{n}$, with zero mean. ${ }^{12}$ The parameter $\beta_{n}$ is distributed in the population with density $f\left(\beta_{n} \mid \theta\right)$, where $\theta$ represents the parameters of the distribution for

\footnotetext{
${ }^{11}$ Andersen (2006) provides analytical proof of a single random coefficient being sufficient for the IIA property not to hold.

${ }^{12}$ Here, we assume that taste is stable over time (i.e. year 2003), but varies over individuals, such that the random taste parameter $\beta_{n}$ varies over households, and not over time. It should also be noted that the parameters contained in $\beta_{n}$ may be either alternative specific or generic over alternatives.
} 
$\beta_{n}$ (i.e. the mean and the variance). The functional form, $f(\cdot)$, is specified by the researcher. Note that in the MMNL, the unobserved part of utility consists of $\xi_{n j t}=\mu_{n}^{\prime} x_{n j t}+\varepsilon_{n j t}$. As in the MNL, the error term $\varepsilon_{j n t}$ is assumed to be iid extreme value. The distribution of $\mu_{n}$, on the other hand, may differ from iid extreme value.

Suppose that the household faces a sequence of repeated choices over time. Let $i$ denote the observed choice by household $n$ at time $t$. Conditional on $\beta_{n}$, the probability of household $n$ choosing alternative $i$ at time $t$ is the standard logit formula, $L_{n i t}\left(\beta_{n}\right)=e^{\beta_{n}{ }^{\prime} x_{n i t}} / \sum_{j} e^{\beta_{n}{ }^{\prime} x_{n j t}}$ (i.e. the MNL choice probability, see McFadden, 1981). The conditional choice probability of household n's sequence of observed choices over time is then the product of the individual logit formulas from each choice occasion $t=1, \ldots, T$. By integrating the conditional choice probability over all possible values of $\beta_{n}$, we have the unconditional choice probability of household $n$ making the observed choice sequence

$$
P\left(y_{n} \mid x, \theta\right)=\int_{\beta_{n}} \prod_{t=1}^{T}\left(\frac{e^{\beta_{n}^{\prime} x_{n i t}}}{\sum_{j} e^{\beta_{n}^{\prime} x_{n i t}}}\right) f\left(\beta_{n} \mid \theta\right) d \beta_{n}=\int_{\beta_{n}} \prod_{t=1}^{T} L_{n i t}\left(\beta_{n}\right) f\left(\beta_{n} \mid \theta\right) d \beta_{n}
$$

Given the purpose of our study, there are a couple of particularly appealing features of the MMNL. First, lagged dependent variables can enter the model without revising the estimation procedure. As highlighted by Train (2002), conditional on $\beta_{n}$, the remaining error terms, $\varepsilon_{\text {jnt }}$, are iid extreme value distributed, i.e. independent over time. A lagged dependent variable in the utility function will, therefore, be uncorrelated with the error terms $\varepsilon_{j n t}$ at time $t$ and the unconditional MMNL choice probabilities remain as stated in equation (2). Second, the MMNL makes it possible to control for unobserved preference heterogeneity, which is important from the point of view of identifying "true state dependence". ${ }^{13}$

\footnotetext{
${ }^{13}$ Heckman (1981) stresses that choice persistence may be a result of both state dependence and preference heterogeneity. Specific characteristics (for instance, having diabetes) may result in a consumer repeatedly choosing non-sweet breakfast cereals. In this case, the choice of non-sweet breakfast cereals is not reinforced by previous choices (i.e. "true state dependence”), but would merely be a result of consumer background variables. In order to identify state dependence, it is therefore important to control for preference heterogeneity.
} 
The household-specific likelihood functions are assumed to be independent, such that the likelihood function to be maximized in the MMNL is the product of all household specific likelihood functions, defined as

$$
L=\prod_{n=1}^{N} \int_{\beta_{n}} \prod_{t=1}^{T} L_{n i t}\left(\beta_{n}\right) f\left(\beta_{n} \mid \theta\right) d \beta_{n}
$$

Our aim is to use maximum likelihood estimation to estimate $\theta$, the parameters describing the distribution of individual $\beta_{n}$ in the population. The integral in equation (3) has no closed form solution, i.e. cannot be calculated analytically, and hence the choice probabilities are approximated through simulation. For further details on the procedure and properties of the simulated choice probabilities, see e.g. Revelt and Train, 1998, Hensher and Greene, 2003, and Hensher et al., 2005. ${ }^{14}$

\section{Estimation and results}

The utility of each choice alternative (flakes, Keyhole-labelled breakfast cereals, muesli, sweet breakfast cereals and others) is assumed to be affected by the price of the particular choice alternative and state dependence, where state dependence is represented by dummy variables for the purchases of the previous and second-previous choice occasions.

To explore the data prior to model specification, we start by estimating an MNL with alternative specific fixed parameters. Of particular interest is whether there is a difference in parameters associated with state dependence for the healthy (Keyhole-labelled) alternative and the unhealthy (sweet) alternative, compared to other breakfast cereal types. We conduct Wald tests with the null hypotheses that the parameters for (i) the dummy variable indicating the previous purchase and (ii) the dummy variable indicating the second-previous purchase

\footnotetext{
${ }^{14}$ In brief, $\beta_{n}$ is drawn repeatedly (R times) from its distribution $f\left(\beta_{n} \mid \theta\right)$. Each value drawn is labelled $\beta_{r}$, where $r=1, \ldots, \mathrm{R}$, and inserted in the following simulated mixed logit choice probability $\hat{\mathrm{P}}\left(y_{n} \mid x, \theta\right)=\frac{1}{R} \sum_{r=1}^{R} \prod_{t=1}^{T} L_{n i t}\left(\beta_{r}\right)$. As stated by Revelt and Train (1998), $\hat{\mathrm{P}}\left(y_{n} \mid x, \theta\right)$ is an unbiased estimator of $\mathrm{P}\left(y_{n} \mid x, \theta\right)$. The parameters are estimated by simulated maximum likelihood. This is done by inserting $\hat{\mathrm{P}}\left(y_{n} \mid x, \theta\right)$ into equation (3), instead of the exact choice probability.
} 
are different between Keyhole-labelled and sweet breakfast cereals, respectively, and other breakfast cereal types. In all cases, we reject the null hypotheses and conclude that, at the 95 percent confidence level, the point estimates of the parameters associated with the dummy variable are equal across alternatives. We therefore estimate generic parameters for all alternatives.

We estimate the following model:

$$
U_{n j t}=\alpha_{n j}+\gamma_{n}^{\prime} D_{p p j, t-1}+\delta_{n}^{\prime} D_{p p j, t-2}+\psi^{\prime} P_{j t}+\varepsilon_{n j t} \quad t=1, \ldots, T
$$

where $U_{n j t}$ is the indirect utility of alternative $j$ ( $j=$ flakes, Keyhole-labelled breakfast cereals, muesli, sweet breakfast cereals or others), for household $n$ at choice occasion $t$. The parameter $\alpha_{n j}$ is the alternative specific constant; $D_{p p j, t-1}$ is a dummy variable that takes the value 1 if alternative $j$ was purchased on the previous choice occasion and zero otherwise; $D_{p p j, t-2}$ is a corresponding dummy variable for having purchased $j$ on the second previous choice occasion, and $P_{j t}$ is the price of alternative $j .{ }^{15}$

The household specific parameters, $\alpha_{n}, \gamma_{n}$ and $\delta_{n}$, consist of two parts; a mean value that is common to all households, and a household specific deviation from the mean. The price parameter is assumed to be fixed over both households and alternatives. Equation (4) can, therefore, be rewritten:

$$
\begin{aligned}
& U_{n j t}=\left(\bar{\alpha}_{j}+\omega_{n j}\right)+\left(\bar{\gamma}+\eta_{n}\right)^{\prime} D_{p p j, t-1}+\left(\bar{\delta}+\mu_{n}\right)^{\prime} D_{p p j, t-2}+\psi^{\prime} P_{j t}+\varepsilon_{n j t}= \\
& \bar{\alpha}_{j}+\bar{\gamma}^{\prime} D_{p p j, t-1}+\bar{\delta}^{\prime} D_{p p j, t-2}+\psi^{\prime} P_{j t}+\underbrace{\omega_{n j}+\eta_{n}^{\prime} D_{p p j, t-1}+\mu_{n}^{\prime} D_{p p j, t-2}+\varepsilon_{n j t}}_{\text {Unobserved part of utility }} \quad t=1, \ldots, T
\end{aligned}
$$

\footnotetext{
${ }^{15}$ Most of the previous studies using a similar methodology to capture state dependence (e.g. Chintagunta, 1993, Erdem, 1996, Ailawadi, 1998, and Sun et al., 2003) include in the model the most recent lagged choice only. However, Seetharaman (2004) shows that restricting the number of lags to only one may lead to biased estimates of the parameters associated with state dependence. Therefore, we choose to include two lags in the model. It should also be noted that the state dependence modelled here means that households could be referred to as "naïve", in the sense that, when making the choice of breakfast cereal at time $t$, they consider their consumption history, but do not recognize the impact of present consumption on future tastes.
} 
Each of the parameters $\omega_{n j}, \eta_{n}$ and $\mu_{n}$ are assumed to be normally distributed with zero mean and constant variance. McFadden and Train (2000) suggest a Lagrange Multiplier test to establish random versus fixed parameters. As noted by Hensher and Greene (2003), another way of testing for random parameters is to use a $t$-test on each estimated standard deviation, as is done here. Note that the distributional assumptions allow the parameters representing habits to take any sign. Household consumption can either be driven by habits or by varietyseeking behaviour (or none of them), such that the sign of these parameters is a matter of empirical investigation. ${ }^{16}$

Each day a household makes a breakfast cereal purchase constitutes a choice occasion. On each choice occasion, the households face prices of both the alternative purchased and the remaining choice alternatives. It is, therefore, necessary to measure the prices associated with all choice alternatives. Unfortunately, we only know the price at which the product purchased was bought, but not the prices of all alternatives faced by the household at that particular choice occasion. As a proxy for the price of the alternatives we use the average weekly price of each alternative that was not purchased. ${ }^{17}$ Note that the price variable will, therefore, be affected by the composition of products purchased by the panel households in a particular week. Due to the potential measurement error in the prices associated with the alternatives not purchased, the estimates of the price parameter should be interpreted with caution. ${ }^{18}$

\footnotetext{
${ }^{16}$ The choice of distribution is not evident; normal, as well as triangular and uniform, distributions allow the estimated parameters to take any sign. Hensher and Greene (2003) note that small differences in estimated moments (for models that assume parameters are normally, uniformly and triangularly distributed) have generally been found in empirical applications of MMNL models, which could imply that the choice among these three distributions may be of little importance. We also estimate the model assuming triangular and uniform distributions. The mean values of the estimated parameters are very similar over the different types of distributions, whereas the value of the estimated standard deviations is generally larger for the uniform (almost double) and triangular distributions (slightly more than double), and highly statistically significant, compared to the estimated standard deviations under the assumption that the parameters follow a normal distribution.

${ }^{17}$ Not all products have been purchased all days of the year. Therefore, average prices are calculated for each week, instead of average daily prices. Because the average prices are used for the alternatives that were not purchased and the actual prices are used for the alternative that was purchased, a relatively large price differences sometimes arises between the alternative chosen and the other alternatives. For example, an expensive product purchased in a convenience store is likely to be matched by relatively expensive alternatives this will not be reflected by the average prices. Therefore, we have also estimated a variant of the model where the price of the observed choice is the average weekly price, instead of the observed price. The parameter estimates associated with the state dependence variables and constants are almost identical to the model described in the text. Even the estimate of the price parameter is similar to that presented in the text (which is based on the observed price) and highly statistically significant.

${ }^{18}$ The measurement error associated with the price variable could potentially affect the other parameter estimates from the model. However, we find that the parameter values of the lagged choice variables are stable over a range of estimated model specifications, containing average or actual prices and different scale factors of the price variable. We interpret this to mean that the parameters for the lagged choice variables are little, if any, affected by the measurement error in the price variable.
} 
The model is estimated using NLOGIT, which is an extension of the econometrics computer program Limdep, and is especially developed to handle discrete choice models. Restrictions in NLOGIT allow a series of maximum 24 purchases for each household to be included in our model. In our sample, a relatively small share of the households (13 percent) made more than 24 purchases during 2003, i.e. are heavy breakfast consumers. Limiting the sample series of observations to a maximum of 24 for the heavy breakfast cereal consumers means running a risk of neglecting potential seasonal effects (structural changes) in breakfast cereal consumption. Therefore, to proceed with NLOGIT, we need to ensure that the risk of seasonal consumption for heavy breakfast cereal consumers is small, i.e. that the results will not depend on our sample of 24 observations chosen for these households. To do so, we consider two different samples; one based on the first 24 purchases during the year for the heavy breakfast consumers and one based on the last 24 purchases. The results show that the parameter estimates are very similar, which imply little or no seasonal variation in breakfast cereal purchases. Formal tests of structural change in consumption over time will be weak due to dependency between the sub samples. Observations in series of either the first 24 or the last 24 purchases overlap for many heavy breakfast cereal consumers, and for those where there is no overlap of observations, the lags in the model cause dependency between the samples in the regressions. To decrease the dependency between the regressions, we estimated a model based on the first 12 observations, for the heavy breakfast cereal consumers, and another model based on the last 12 observations, for the same households. Thereafter, we perform a Wald-test for structural change, where the null hypothesis is that there is no difference in the parameters estimated by the two regressions. We cannot reject the null hypothesis. We conclude that the risk of seasonal effects in breakfast cereal consumption for heavy breakfast cereal consumers is small, and therefore choose to carry on the analysis by using NLOGIT. The results reported below are based on a sample series of the first 24 purchases during the year, for those households who purchased breakfast cereals more than 24 times during the study period. 
The estimation results from the MMNL are shown in Columns $2-3$ of Table $3,{ }^{19}$ and $t$-values are shown within brackets. ${ }^{20}$ For the random parameters, we estimated both the mean and standard deviations. The parameter estimates of the MMNL model in Table 3 provide information on the population profile, i.e. the distribution of parameter values across households purchasing breakfast cereals. Due to the statistically significant estimates of the standard deviations for both the alternative specific constants and the parameters associated with state dependence, our results imply heterogeneity in preferences over consumers. This is in line with the findings of several previous studies; e.g. Andersen (2006) Chidmi and Lopez (2007) Nevo (2001) and Chintaguanta (1993) all report heterogeneity in preferences, and heterogeneity in state dependence, specifically, is found by e.g. Erdem (1996). A positive parameter estimate implies that utility increases as the corresponding variable increases and, thus, the probability of the household purchasing the product. Noteworthy is the pseudo-R2 adjusted value of 0.40 , suggesting a decent explanatory power.

The point estimate of the price parameter is negative and statistically significant, suggesting that the typical household in the sample experiences a decrease in utility (and hence a negative effect on the probability of purchasing a breakfast cereal) from a marginal increase in the price of this particular breakfast cereal. ${ }^{21}$ Also, the results show that, on average, having purchased the particular breakfast cereal type on the previous or second previous choice occasion positively affects the utility of the particular breakfast cereal, implying habit persistence in breakfast cereal consumption. We also find statistically significant

\footnotetext{
${ }^{19}$ The simulated maximum likelihood estimation was performed using the Standard Halton Sequence (SHS), which is a draw method that, compared to random draws, reduces the risk of drawing parameter values from a limited part of the specified distribution, and thereby reduces the number of draws needed for estimation (for details, see e.g. Train, 1999) . Here, we make 100 Halton draws of $\beta_{n}$ from its distribution $f\left(\beta_{n} \mid \theta\right)$. The number of iterations needed for model convergence is 61 . To determine the overall statistical significance of the model, an LL-ratio test was performed, where the estimated model was compared to a model that includes the alternative specific constants only. The resulting $\chi^{2}$ statistic equals 11,881 with 79 degrees of freedom, and the $p$-value is zero, implying that the estimated model significantly improves the log-likelihood function, compared to a model containing constants only.

${ }^{20}$ For comparison, we also report the results from a MNL model in the table, see column 1 . The parameter values produced by the MNL are used as starting values for the simulated maximum likelihood estimation of the parameters of the MMNL model. The parameter estimates from the MNL model could also be regarded as a robustness test of the results. As shown, the qualitative results are the same in the MNL and the MMNL models.

${ }^{21}$ Our results imply that a SEK 10 increase in the price per 100 gram of flakes reduces the choice probability of flakes by 0.1 percentage points. Correspondingly, a SEK 10 increase in the price of Keyhole labelled cereals reduces the choice probability for Keyhole labelled cereals by 0.04 percentage points; a SEK 10 increase in the price of muesli reduces the choice probability for muesli by 0.07 percentage points, a SEK 10 increase in the price of sweet cereals reduces the choice probability for sweet cereals by 0.05 percentage points, and, finally; a SEK 10 increase in the price of "others" reduces the choice probability for "others" by 0.03 percentage points.
} 
heterogeneity in the response of households, suggesting that households differ from the population mean.

Based on the results in columns 2-3, we calculate the marginal utility effects of having chosen this particular cereal on the previous and second previous choice occasions. The sample distributions of marginal effects from the previous choices are presented in Figure 1B and 2B in Appendix B. ${ }^{22}$ Figure 1B shows that the consumption by the majority of households is associated with habit persistence (the marginal utility of having purchased a breakfast cereal type on the previous choice occasion is positive), but that there are households that value variety as well, i.e. for whom the marginal utility of having purchased a breakfast cereal on previous choice occasions is negative. As shown by Figure 2B, the marginal effects of having purchased a product two choice occasions ago are very similar to those of having purchased the product on the previous choice occasion.

The finding of relatively strong habit persistence is in line with previous studies based on disaggregate product data. The absolute value of the parameter estimates found here are, however, not directly comparable to results in previous studies, both because previous studies only include one lag of the choice variable, and because model specifications are slightly different. For instance, Sun et al., 2003, include a dummy for the most recent lagged choice and, depending on the model specification, find estimates of structural state dependence ranging between 1.76 and 2.40 for ketchup, which is higher than the mean estimates presented here for the previous choice occasion.

We also attempt to explain (at least part of) the variation in state dependence across consumers, and to distinguish observed differences in state dependence from other sources of preference heterogeneity. We do so by interacting both the constant and the state dependence variables with observed household characteristics (income, education, as well as number of children and adults). More specifically, we try to identify the household types with characteristics that affect the utility associated with the particular breakfast cereal, as well as the household types whose consumption exhibits particularly strong habit persistence. We thereby allow for different mean parameters over household groups. The omitted groups are Lowest income, Elementary schooling and Single. The results are shown in columns 2-3 of

\footnotetext{
${ }^{22}$ The formula used for calculating the marginal utility is $\bar{\beta}+\sigma \times N$, where $\bar{\beta}$ is the mean estimate, $\sigma$ is the standard deviation and $N$ has a standard normal distribution.
} 
Table 3 below. Parameter estimates that are not statistically significant at the 10 percent level are not reported here.

The parameter estimates associated with the interaction terms between the measures of state dependence and household characteristics are generally not statistically significant. The exception is that the utility of choosing a breakfast cereal seems to be less affected by having purchased the cereal on previous choice occasions if the household consists of two adults with children (both one child and two or more children) than if the household consists of a single adult with no children. Also, households with high school education and higher education seem to be less affected by the purchase on previous choice occasions, compared to households with the lowest education. The strength of the habit persistence does not seem to be affected by income.

Regarding the interaction terms between the alternative specific constants and the household characteristics, the results suggest that the utility from sweet breakfast cereals is positively affected if the household includes children. Adding more adults to the household seems to have a negative effect on the utility derived from Keyhole-labelled breakfast cereals. For muesli, the qualitative findings are the same as for Keyhole-labelled breakfast cereals. In addition, it seems that the utility of choosing muesli is positively affected if the person responsible for food purchases has a high school or higher education. Also, households belonging to the highest income group derive a higher utility from choosing muesli than lowincome households. 
Table 3. Utility parameter estimates

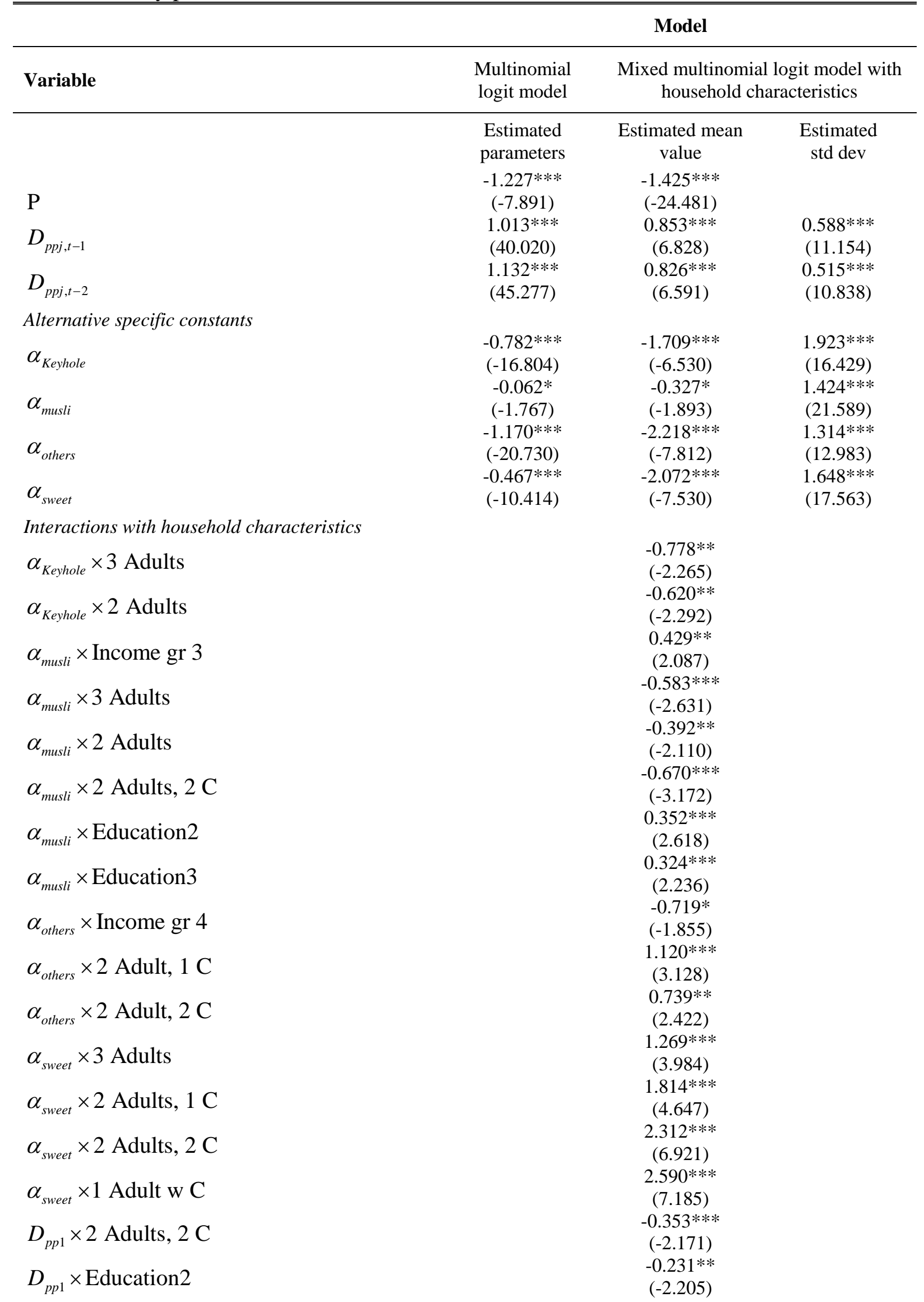


Table 3 continued:

$\begin{array}{lc}D_{p p 2} \times 2 \text { Adults, 2 C } & -0.291^{*} \\ D_{p p 2} \times 1 \text { Adult w C } & (-1.707) \\ D_{p p 2} \times \text { Education2 } & -0.459^{* *} \\ D_{p p 2} \times \text { Education3 } & -2.158) \\ & -0.188^{*} \\ & (-1.864) \\ & -0.256^{* *} \\ & (-2.312)\end{array}$

Pseudo R-squared adjusted

0.23

0.40

Superscripts ${ }^{* * *},{ }^{* *}$ and $*$ imply statistical significance at the 1,5 and 10 percent level, respectively.

A range of alternative models were also estimated, where the alternative specific constants are fixed and the parameters associated with state dependence are random (with and without being interacted with household characteristics), and models where the alternative specific constants are random and the parameters associated with state dependence are fixed (with and without being interacted with household characteristics). The comparable qualitative findings remain, and we conclude that the findings reported in Table 3 appear to be robust.

\section{Discussion}

We estimate the strength and heterogeneity over households in state dependence associated with breakfast cereal consumption, where positive state dependence implies habit persistence and negative state dependence implies variety-seeking in breakfast cereal consumption. Our results suggest that habits are a very important determinant of breakfast cereal choices. There seems to be a strong element of habit persistence in breakfast cereal choices for all breakfast cereal types. In addition, our results suggest that there is a significant variation across households in the strength of habit persistence, meaning that single (mean) parameters representing state dependence are insufficient in representing household behavior. Consumption by the average household is strongly habitual, but there are households where consumption is better described as variety-seeking.

The relative shares of consumption of the breakfast cereal types seem to be similar over income and educational groups. However, households with many children have a higher consumption of sweet cereals and lower consumption of Keyhole-labelled breakfast cereals than households with no children. If aiming at improving the nutritional quality of breakfasts, households with many children might therefore be a target group. 
We also add interaction variables between the measure of state dependence and observed household characteristics, such as income, education and the number of children and adults in the household. The idea is to examine (as far as the data allow) whether differences in state dependence can be attributed to observed characteristics. In general, these interaction effects have little influence on the choice of breakfast cereals, suggesting that it may be necessary to look beyond these characteristics in order to explain differences in the strength of state dependence. Habit persistence appears to be the weakest for two-adult households with children compared to single-adult households without children. This could be an indicator of habit persistence being weaker for households with children, compared to those without. However, the comparison of relative strength of habit persistence over household types should be interpreted with caution. Habit persistence as defined here may also reflect a greater preference heterogeneity within households with more individuals and both adults and children (relative to households consisting of adults only), and not necessarily weaker habit persistence for single individuals in the household.

Our results support the literature that finds habit persistence in food consumption. Typically, habit persistence is found in data sets containing disaggregated product data and, to a lesser extent, when habit persistence is analyzed using more aggregate product data. Our results imply that the "stickiness" of consumption (habit persistence) should be taken into account when developing policies to address consumption of certain food categories. For instance, consumer response to tax reforms (e.g. subsidizing Keyhole-labelled foods), or information campaigns aimed at encouraging a healthier food consumption, will be affected by the degree of habit persistence associated with both the Keyhole-labelled foods and the less healthy substitutes. The higher the degree of habit persistence, the larger the difference between short and long term consumer responses to permanent relative price changes, and the more forceful the policy instruments need to be in order to redirect consumption in the short run.

The estimated price parameter is relatively small, implying that the probability of purchasing breakfast cereals is little affected by price changes. This might be due to breakfast cereals being a relatively inexpensive product that represents only a small budget share (see Nordström and Thunström, 2008), such that households pay little attention to price increases in breakfast cereals. 
Important issues for future research are to extend the analysis to include a wider range of food groups, in order to gain information on differences in habit persistence associated with consumption of particularly healthy food products and unhealthy food products. Here, the analysis could be based both on habit persistence in consumption of specific nutrients, as well as in products. It would also be of interest to analyze the extent to which habits stick over the consumer's life cycle. Finally, it would be valuable to gain information on what policies (i.e. price or information mechanisms) are most effective in influencing consumption associated with habit persistence. Here, experimental methods (e.g. choice experiments) may be helpful. All these issues are important for policy makers to understand when designing policies aimed at encouraging a healthier food consumption. 


\section{References}

Ailawadi, K.L. and Neslin, S.A. (1998) The Effect of Promotion on Consumption: Buying More and Consuming It Faster, Journal of Marketing Research, XXXV: 390-398.

Alessie, R. and Kapteyn, A. (1991) Habit Formation, Interdependent Preferences and Demographic Effects in the Almost Ideal Demand System, The Economic Journal, 101(406): 404-19.

Andersen, L. M. (2006) Consumer Evaluation of Environmental and Animal Welfare Labelling: An Econometric Analysis on Panel Data Using Mixed Multinomial Logit, Working Paper No 6, Akf Copenhagen.

Bath, C.R. (1997) An Endogenous Mode Choice Model with an Application to Intercity Travel, Transportation Science, 31(1): 34-48.

Browning, M. and Collado, D.M. (2007) Habits and Heterogeneity in Demands: a Panel Data Analysis, Journal of Applied Econometrics, 22(3): 625-40.

Carrasco, R., Labeaga, J.M. and Lopez-Salido, J.D. (2005) Consumption and Habits: Evidence from Panel Data, The Economic Journal, 115(1): 144-65.

Chidmi, B. and Lopez, R.A. (2007) Brand-Supermarket Demand for Breakfast Cereals and Retail Competition, American Journal of Agricultural Economics, 89(2): 1-14.

Chintagunta, P.K. (1993) Investigating Purchase Incidence, Brand Choice and Purchase Quantity Decisions of Households, Marketing Science, 12(2): 184-208.

Dynan, K.E. (2000) Habit Formation in Consumer Preferences: Evidence from Panel Data, American Economic Review, 90(3): 391-406.

Erdem, T. (1996) A Dynamic Analysis of Market Structure Based on Panel Data, Marketing Science, 15(4): 359-78. 
Heckman, J.J. (1981) Heterogeneity and State Dependence, in S. Rosen (Ed.), Studies in Labor Markets, University of Chicago Press, 91-139.

Hensher, D.A. and Greene, W.H. (2003) The Mixed Logit Model: the State of Practice, Transportation, 30: 133-76.

Hensher, D.A., Rose J.M. and Greene, W.H. (2005) Applied Choice Analysis. Cambridge University Press.

Hensher, D.A., Rose, J.M. and Greene, W.H. (2007) Combining RP and SP data: biases in using the nested logit 'trick'- contrasts with flexible mixed logit incorporating panel and scale effects, Journal of Transport Geography

Jenkins, D.J.A., Wolever, T.M.S., Taylor, R.H., Griffiths, C., Krzeminska, K., Lawrie, J.A., Bennett, C.M., Goff, D.V., Sarson, D.L. and Bloom, S.R. (1982) Slow Release Dietary Carbohydrate Improves Second Meal Tolerance, American Journal of Clinical Nutrition, 35: 1339-46.

Johannesson, M. and Lundin, D. (2002) The Impact of Physician Preferences on the Prescription of New Drugs, SSE/EFI Working Paper Series in Economics and Finance No 460.

Kenkel, D.S. and Manning, W. (1999), Economic Evaluation of Nutrition Policy - Or, There’s No Such Thing as a Free Lunch, Food Policy, 24(2): 145-162.

Liljeberg, H., Åkerberg, A. and Björck, I. (1999) Effect of the Glycemic Index and Content of Indigestible Carbohydrates of Cereal-Based Breakfast Meals on Glucose Tolerance at Lunch in Healthy Subjects, American Journal of Clinical Nutrition, 69: 647-55.

Liu, S., Willet, W.C. and Stampfer, M.J. (2000) A Prospective Study of Dietary Glycemic Load, Carbohydrate Intake, and Risk of Coronary Heart Disease in US Women, American Journal of Clinical Nutrition, 71:1455-61. 
Liu, S., Willett, W.C., Manson, J.E., Hu, F.B., Rosner, B. and Colditz, G. (2003) Relation between Changes in Intake of Dietary Fibre and Grain Products and Changes in Weight and Development of Obesity among Middle-Aged Women, American Journal of Clinical Nutrition, 78(5): 920-27.

Livsmedelsverkets föreskrifter och allmänna råd om användning av viss symbol. SLVFS 1989:2.

Meghir, C. and Weber, G. (1996) Intertemporal Nonseparability or Borrowing Restrictions? A Disaggregate Analysis Using a U.S. Consumption Panel, Econometrica, 64(5): 1151-81.

McFadden, D. (1981) Econometric Models for Probabilistic Choice, in Structural Analysis of Discrete Data with Econometric Applications, Charles F. Manski and Daniel McFadden, eds. Cambridge, MIT Press, 198-272.

McFadden, D. and Train, K. (2000) Mixed MNL models for discrete response, Journal of Applied Econometrics, 15: 447-470.

Nevo, A. (2001) Measuring Market Power in the Ready-to-Eat Cereal Industry, Econometrica, 69(2): 307-342.

Nilsson, A.C., Östman, E.M., Granfeldt, Y. and Björck, I. (2008) Effect of Cereal Test Breakfasts Differing in Glycemic Index and Content of Indigestible Carbohydrates on Daylong Glucose Tolerance in Healthy Subjects, American Journal of Clinical Nutrition, 87: $645-54$.

Nordström, J. and Thunström, L. (2008) Effects on Different Household Types of Economic Policies Designed to Encourage a Healthier Food Consumption, Mimeo. 
Persson U., Svensson, M. and Ödegaard, K. (2004), Kostnadsutveckling i Svensk Sjukvård Relaterad till Övervikt och Fetma - Några Scenarier. Vårdens Resursbehov och Utmaningar på Längre Sikt., Stockholm: Landstingsförbundet.

Persson, U. and Ödegaard, K. (2005), Indirekta Kostnader till Följd av Sjukdomar Relaterade till Övervikt och Fetma, IHE e-rapport 2005(3).

Pollack, R.A. (1970) Habit Formation and Dynamic Demand Functions, Journal of Political Economy, 78: 745-63.

Revelt, D. and Train, K. (1998) Mixed logit with repeated choices: Households' choices of appliance efficiency level The Review of Economics and Statistics, 80: 1-11.

Salmeron, J., Ascherio, A, Rimm, E.B., Colditz, G.A., Spiegelman, D., Jenkins, D.J., Stampfer, M.J., Wing, A.L. and Willett, W.C. (1997) Dietary Fibre, Glycemic Load and Risk of NIDDM in Men, Diabetes Care, 20: 545-50.

Salmeron, J., Manson, J.E., Stampfer, M.J., Colditz, G.A., Wing, A.L. and Willett, W.C. (1997) Dietary Fibre, Glycemic Load and Risk of Non-Insulin-Dependent Diabetes Mellitus in Women, Journal of the American Medical Association, 277: 472-77.

Schatzkin, A., Mouw, T., Park, Y., Subar, A.F., Kipnis, V., Hollenbeck, A., Leitzmann, M.F. and Thompson, F.E. (2007) Dietary Fibre and Whole-Grain Consumption in Relation to Colorectal Cancer in the NIH-AARP Diet and Health Study, American Journal of Clinical Nutrition, 85(5): 1353-60.

Seetharaman, P.B. (2004) Modeling Multiple Sources of State Dependence in Random Utility Models: A Distributed Lag Approach, Marketing Science, 23(2): 263-71.

Siddhartha, C., Seetharaman, P.B. and Strijnev, A. (2004) Model of Brand Choice with NoPurchase Option Calibrated to Scanner-Panel Data, Journal of Marketing Research, XLI, 18496. 
Socialstyrelsen (2003) Hälso- och sjukvård. Lägesrapport 2003.

Sun, B., Neslin, S.A. and Srinivasan, K. (2003) Measuring the Impact of Promotions on Brand Switching When Consumers Are Forward Looking, Journal of Marketing Research, XL: 398-405.

Train, K. (1999) Halton Sequences for Mixed Logit, Manuscript, Department of Economics, University of California, Berkeley.

Train, K. (2002) Discrete Choice Methods with Simulation, Cambridge University Press. 


\section{Appendix A}

Table A1. Variable definitions

\begin{tabular}{|c|c|}
\hline Variable name & Definition \\
\hline Price & $\begin{array}{l}\text { Price per } 100 \text { gram of the product purchased for the } \\
\text { observed choice, average weekly price per } 100 \text { gram for } \\
\text { the alternatives. Prices are in SEK (expressed in units of } \\
\text { SEK divided by } 10 \text { )* }\end{array}$ \\
\hline$D_{p p j, t-1}$ & $\begin{array}{l}1 \text { if the breakfast cereal type was purchased on the last } \\
\text { consecutive choice occasion, zero otherwise }\end{array}$ \\
\hline$D_{p p j, t-2}$ & $\begin{array}{l}1 \text { if the breakfast cereal type was purchased on the second } \\
\text { last consecutive choice occasion, zero otherwise }\end{array}$ \\
\hline Single & $\begin{array}{l}1 \text { for households consisting of a single adult without } \\
\text { children, zero otherwise }\end{array}$ \\
\hline 2 Adults & $\begin{array}{l}1 \text { for households consisting of two adults without } \\
\text { children, zero otherwise }\end{array}$ \\
\hline Single with Children & $\begin{array}{l}1 \text { for households consisting of a single adult with one or } \\
\text { more children, zero otherwise }\end{array}$ \\
\hline 2 Adults, 1 Child & $\begin{array}{l}1 \text { for households consisting of two adults with one child, } \\
\text { zero otherwise }\end{array}$ \\
\hline 2 Adults, 2 Children & $\begin{array}{l}1 \text { for households consisting of two adults and two or } \\
\text { more children, zero otherwise }\end{array}$ \\
\hline 3 Adults & $\begin{array}{l}1 \text { for households consisting of three or more adults, zero } \\
\text { otherwise }\end{array}$ \\
\hline Elementary schooling & $\begin{array}{l}1 \text { for households where the maximum level of education } \\
\text { for the person mainly responsible for food purchases is } \\
\text { elementary schooling, zero otherwise }\end{array}$ \\
\hline High school education & $\begin{array}{l}1 \text { for households where the maximum level of education } \\
\text { for the person mainly responsible for food purchases is } \\
\text { high school education, zero otherwise }\end{array}$ \\
\hline Higher education & $\begin{array}{l}1 \text { for households where the maximum level of education } \\
\text { for the person mainly responsible for food purchases is } \\
\text { university education, zero otherwise }\end{array}$ \\
\hline Education,na & $\begin{array}{l}1 \text { if household has not reported the level of education, } \\
\text { zero otherwise }\end{array}$ \\
\hline Income group 1 (lowest) & $\begin{array}{l}1 \text { for households with maximum yearly income of SEK } \\
\text { 199,999, zero otherwise }\end{array}$ \\
\hline Income group 2 & $\begin{array}{l}1 \text { for households with yearly income SEK 200,000- } \\
\text { 299,999, zero otherwise }\end{array}$ \\
\hline Income group 3 & $\begin{array}{l}1 \text { for households with yearly income SEK 300,000- } \\
\text { 499,999, zero otherwise }\end{array}$ \\
\hline Income group 4 (highest) & $\begin{array}{l}1 \text { for households with yearly income of minimum SEK } \\
500,000 \text {, zero otherwise }\end{array}$ \\
\hline
\end{tabular}

* On January $10^{\text {th }} 2008$, USD/SEK $=6.36$. Prices are calculated as the average price of all products, in each of the five categories, purchased by the households in the sample in a given week. 
Table A2. Relative share of household types in the sample, compared to the sample in the full GfK panel of grain consumers (who stayed in the panel for the full year)

\section{Variable name}

Single

2 Adults

Single with Children

2 Adults, 1 Child

2 Adults, 2 Children

3 Adults

Sum

Elementary schooling

High school education

Higher education

Education,na

Sum

Income group 1 (lowest)

Income group 2 ( $2^{\text {nd }}$ lowest $)$

Income group 3 ( $2^{\text {nd }}$ highest)

Income group 4 (highest)

Sum
Relative share of those purchasing breakfast cereals

0.29

0.37

0.04

0.06

0.11

0.13

1.00

0.28

0.43

0.29

0.01

1.00

0.25

0.26

0.35

0.14

1.00
Relative share of the full GfK panel for 2003
0.36

0.36

0.03

0.06

0.08

0.11

1.00

0.33

0.40

0.26

0.01

1.00

0.30

0.26

0.29

0.11

1.00 


\section{Appendix B}

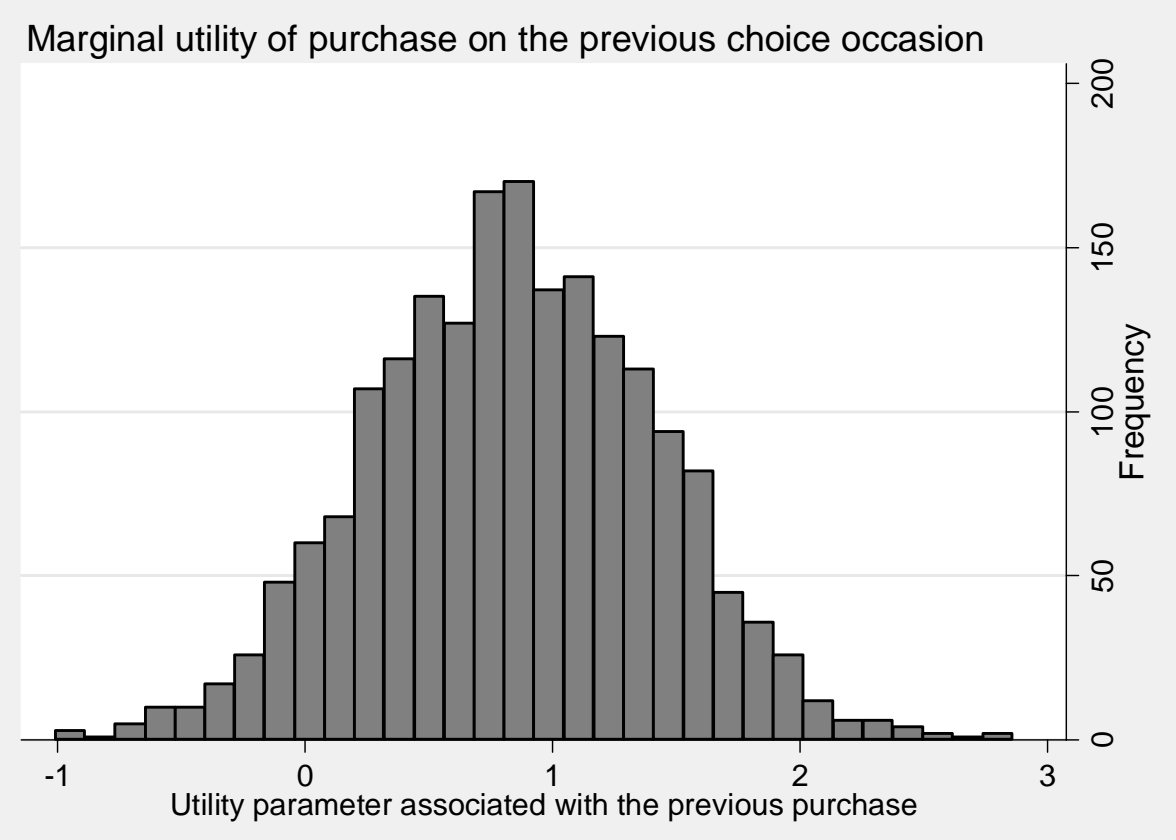

Figure 1B. Estimated distribution of the coefficient for purchase on the previous choice occasion

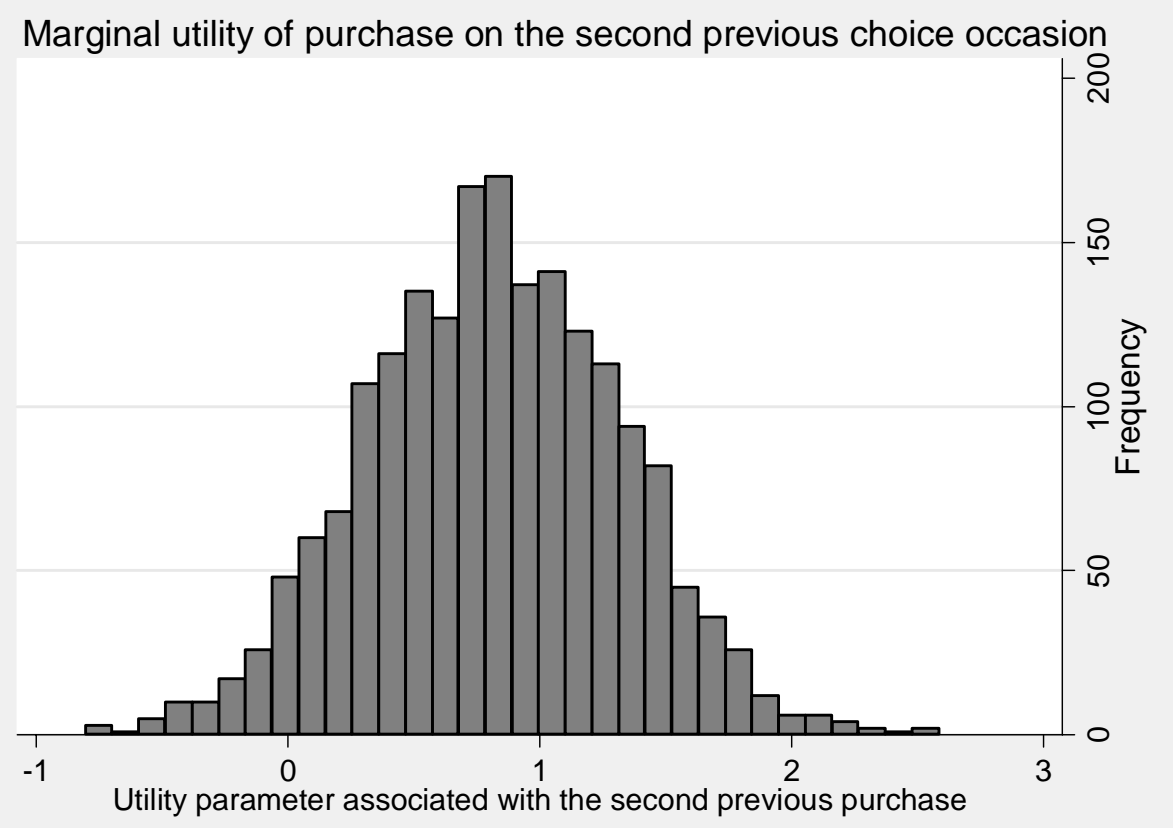

Figure 2B. Estimated distribution of the coefficient for purchase on the second previous choice occasion 